\title{
Cultural health practices of South African Vatsonga people on the home care of children with measles
}

\author{
RT Lebese, MA Cur Student, University of Venda for Science and Technology \\ VO Netshandama, MA Cur, University of Venda for Science and Technology \\ NS Shai-Mahoko, Professor, University of Venda for Science and Technology
}

\section{Abstract}

The purpose of this research study was to identify the cultural health practices of the Vatsonga in relation to the home care of children with measles. It was undertaken in the Giyani District of the Limpopo Province, in the Republic of South Africa. The qualitative, explorative and contextual design was used to conduct this project. Data was collected from nine key informants and nineteen general informants. Data was collected using individual interviews with key-informants and focus group interviews with general informants. Observations were also made.

The findings revealed that the Vatsonga still provide home care for children with measles. Those who care for the sick children are women - either the mother of the sick child or an elderly woman with knowledge of the disease. There are different cultural practices that the Vatsonga observe when there is a child suffering from measles. These include isolation of the child, restriction of sexual intercourse, giving of a milk diet to the sick child and performance of a cultural ceremony at the resolution of the disease. Similarities and differences between hospital and home-based care were identified. Recommendations were made using Leininger's three modes of decision making as explained in the Sunrise Model, which include the following:

- cultural care preservation or maintenance;

- cultural care accommodation or negotiation;

- cultural care repatterning or restructuring.

\section{Nkomiso}

(Tsonga translation of the English abstract)

Ndzavisiso lowu a wu languta ndlela ya ndhavuko leyi vana va Vatsonga va ongoriwaka ha yona ekaya loko va ri ni Ximungwa-mungwana/Mungu. Ndzavisiso lowu wu endliwile kwala Africa-Dzonga eka xifundzha-nkulu xa N'walungu, exifundzeni xa Giyani. Timhaka leti ti tshahiwile hi ndlela ya ku vutisa munhu loyi a nga tshama a ongola vana lava va nga vabya ximungwa-mungwana emakaya, ni ku vutisa vanhu lava va nga ni vutivi hi maongolelo ya Ximungwa-mungwana ekaya hi mintlawa. Timhaka ti tshahiwile nakambe hi ku langutisa.

Ndzavisiso wu komba leswaku, vatsonga va ha hlayisa vana va ximungwa-mungwana ekaya. Vana va hlayisiwa hi vavasati ku nga va mana wa nwana kumbe mukhegulu loyi anga ni vutivi byo hlayisa nwana wa mungu. Ku ni mahlayiselelo yo hambana-hambana ku ya hi ndzavuko ya vatsonga yo hlayisa vana va Ximunga-mungwana. Mahlayiselelo ya katsa swinwana swa swilo leswi swi landzelaka. Vana lava va hlayisiwaka va pfaleriwa endlwini, masango ya songiwa, vana va nyikiwa masi yo hisa leswaku ya susa swirhumbani. Loko mungu wu hela n'wana wa hlantswiwa hi nhlangulo emahandzeni ya tindlela. Eka ndzavisiso lowu ku kumekile swilo swo tala leswi swi fanaka eku hlayiseni ka vana va mungu exikarhi ka Vatsonga na xibedlhela.

Eka ndzavisiso lowu hi kumile ku ri ni maendlelo ya Vatsonga lawa ya fanaka ni maendlelo ya Xibedhlele. Switsundzuxo hi mahlayiselelo ya vana swi endliwile hi $\mathrm{ku}$ landzelela maendlelo manharhu ya Leininger ya nkunguhato wa 'Sunrise Model lawa ya landzelaka:

- $\quad$ ku hlayisa maongolelo ya ndhavuko

- $\quad$ ku amukela maongolele ya ndzavuko

- $\quad$ ku cinca maongolelo ndzavuko

\section{Background and rationale}

Different remedies for health problems are used in South Africa. There are vast numbers of values and beliefs about health practices in respect of specific diseases and illnesses. Cultural practices seem to play an important role in health and illness. Since culture is to a large extent a blueprint for determining decision making, the Vatsonga people would be expected to conform to their cultural beliefs and practices when ill (Sampson, 1982:15).

According to Vatsonga culture, there are certain illnesses that tend to resolve spontaneously, and those that require 
treatment to be resolved. The recovery process seems to be hastened through the use of certain medicinal plants and compounds. Within each family, there may be an individual with good knowledge of these medicinal plants. This person is able to prepare the necessary medicinal compounds for the sick. However, if the sick person does not recover as expected or if the member of the family regularly falls ill, the help of ' $n$ 'anga' or 'mungoma' will be sought (Kriel \& Hartman, 1991:30).

The majority of the Vatsonga in the rural areas either go to the traditional healer, herbalist or traditional caregiver, whilst the majority of those residing in the urban areas prefer to go to the conventional medical practitioner. According to the Vatsonga people, there are two important categories of agents that cause illness, namely:

- dissatisfied ancestral spirits (swikwembu) \&

- evil sorcerers.

If the ancestral spirits concerned and the reason for the dissatisfaction can be identified, a reconciliatory offering will be made. If the ( $N d z a w u)$ spirits are identified as the cause of the illness, healing can take place if the spirit is allowed to possess the sick person. The latter can act as a medium through which the ancestral spirits may communicate with the living (Kriel \& Hartman, 1991:31). Reversal of 'sorcery' can be enhanced through the use of magic portions. Alternatively the patient may be strengthened with certain medicines so that the 'evil' influences cannot 'harm' $\mathrm{him} / \mathrm{her}$ any further. This type of medicine is occasionally used as a protective measure against the influence of 'evil' sorcerers. In this instance, there are diseases such as rigoni, xifulwa and fukuzani for which people do not seek conventional care because they believe that the cause is witchcraft. They normally seek care from traditional healers. These cultural beliefs and practices seem to influence the decision that people take when they are ill. They further determine whom to consult and where to go for treatment (Kriel \& Hartman, 1991:31).

The decision that people take regarding where to go for treatment, is also influenced by members of the family. The dominant role is played by an elderly person or a male person who is the head of the family. It is also the male person or elderly family member who takes the sick person to the place where treatment is to be offered. This results in most women complying with instructions from the 'head' of the family or key role player. In most cases the women do not get involved in deciding about the health care of their children or themselves.

There are some specific occurrences of disease that are regarded as normal. These include measles, mumps and convulsions. According to the Vatsonga, each child should suffer from these ailments. This belief may influence the way in which the Vatsonga children with measles are cared for (Vlok, 1996: 35).

The Vatsonga normally care for the sick children at home, especially when they suffer from diseases such as measles, mumps and convulsions. They normally seek care at a later stage, on realising that complications have set in. This cultural outlook influences the way in which a child with measles is treated. A visit to the clinic for immunisation or the hospital for treatment is done in response to the severity of the attack of measles. The late referral of children with measles may lead to admission when complications such as bronchitis, blindness, bronco-pneumonia and encephalitis have reached an advanced stage, and death may be imminent.

\section{Statement of the problem}

Measles is one of the communicable diseases that are still rife in South Africa despite the Expanded Immunisation Programme (EPI), where clinics provide free services for all children under the age of five years. About 50 percent of children under the age of five are immunised against polio, measles, tetanus and whooping cough. It is also estimated that 50 percent of children in other developing countries like Zimbabwe and Zambia are also vaccinated against infectious diseases (Boyle \& Andrews, 1995:419). It is estimated that death from vaccine preventable diseases like measles, diphtheria and tuberculosis accounts for twentyfive percent $(25 \%)$ of the total mortality from acute respiratory infections (Kibel \& Wagstaff, 2001: 221).

According to national statistics there is a marked decline in the number of measles cases reported however it should be noted that there are measles cases in the rural areas that are still nursed at home and this is not reported. The statistics indicate that there were 83 cases in 2000,31 cases in 2001 and 18 cases in 2002. During the time of this study measles statistics for the Lowveld Region where the Greater Giyani District is located, revealed 1207 reported cases in 1997. Four hundred and eleven (411) children suffered from measles between January and April 1998. These statistics are from the predominantly rural regions namely, Lowveld region; Northern region; Westem region; Eastern region; and Southern region (Limpopo Province Department of Health Statistics, 1998: 4).

The personal experience of the researcher while working at the clinic revealed that most children were still cared for at home by traditional caregivers. The number of children admitted to the hospital or clinics with complications due to measles, implies that the care that the Vatsonga give to children with measles may not be adequate. It is also an indication that the traditional caregivers are still ignorant of how to prevent some of the complications. As a result there is a need to explore the cultural health practices regarding the care of children with measles at home. This study will attempt to answer the following questions:

- What are the cultural health practices of the Vatsonga with regard to caring for children with measles at home?

- What are the cultural health practices of the Vatsonga that are beneficial to the community with regard to the care of children with measles?

- What are the cultural health practices of the 
Vatsonga that are not beneficial to the community with regard to the care of children with measles?

\section{Purpose of the study}

The purpose of this study was to explore the cultural health practices of the Vatsonga people in relation to the care of children with measles at home.

\section{Objectives of the study}

The objectives of the study were to:

- determine cultural health practices of Vatsonga in relation to care of children with measles at home

- identify the cultural caring practices of children with measles that are beneficial to Vatsonga community

- develop guidelines that will assist the Vatsonga to enhance practices that can be beneficial for the community and modify practices that are harmful

- $\quad$ provide an information pool for health education actions.

\section{Theoretical departure}

This research has been conceptualised from Leininger's trans-cultural health care model (Leininger, 1991:43). The goal of Leininger's theory and the Sunrise model is to provide culture-congruent care.

Leininger's (1991:41) model takes into consideration individuals and groups, their beliefs and value systems. These specific cultural practices form the basis or the means through which the delivery of satisfactory health care to the people can be accomplished (Leininger, 1991:41). Leininger (1991:41) believes that if nurses had knowledge of many cultures, it would be possible to teach and provide care that is congruent with the people's way of life rather than the 'emic' imposition or culturally bound professional practices (Leininger, 1991:41).

Through the use of Leininger's theory and the Sunrise conceptual model, the researcher can discover meanings of care specific to the Vatsonga culture, in relation to the care of children with measles. This will provide health care workers with knowledge of how to provide meaningful care that satisfies the cultural needs of Vatsonga children with measles.

Leininger states that if one studies the meanings, forms and expressions of cultural care, one can better understand care and predict the health or well being of individuals, families and communities (Leininger, 1991:41). Leininger (1991:41) further contends that from the clients' worldview, social structure components and environmental factors, three modes of cultural care decisions and actions can be predicted to guide health care. The three modes of cultural care which shall be utilised to analyse the cultural health practices of the Vatsonga people are as follows:

- cultural care preservation or maintenance

- cultural care accommodation or negotiation, and

- cultural care repatterning or restructuring
(Leininger,1991:41).

\section{Research design and methods}

The research design for this study is qualitative, explorative and contextual. It is conducted to describe and promote understanding of human experiences (Morse \& Field, 1996:8-9; Leininger, 1991: 38). The qualitative research method allowed the researcher to gain more knowledge of the problem under study because the researcher used unstructured observation and interviews to obtain data from the informants, and this facilitated a holistic approach. The approach was also selected because the main aim of this study was to generate in-depth knowledge with regard to care by the respondents, of children with measles at home (Leininger, 1991: 38).

The study was conducted in a naturalistic setting at the homes of the Vatsonga. The aim was to identify the underlying assumptions and attitudes of the Vatsonga in relation to measles. The researcher needed to be aware of the respondents' knowledge about care of children with measles at home so as to accurately assess, know and understand their inner world and to design and implement culturally congruent care that could lead to wellness or health. The only method that could cater for these requirements was the qualitative method, and hence its use in this research (Morse \& Field, 1996:8-9) ; (Leininger, 1991: 38).

The method allowed the researcher the opportunity to gather information by letting the people narrate their experiences. The causes of measles, identification of the disease, cultural management and complications were shared.

\section{Explorative}

Exploratory research is an extension of descriptive research that focuses directly on the discovery of relationships. The researcher engaged in exploratory study because of the desire to get a richer understanding of the phenomena under study.

The researcher wanted to gain more information with regard to the experiences of the informants. The factors that influence the occurrence of measles, factors that determine the type of care given to children with measles, and factors that may lead to the occurrence of complications were explored.

\section{Contextual}

The study was contextual because it focussed on a specific cultural group namely the Vatsonga. The study also focussed on the home care of children with measles by the Vatsonga, and did not look into the home care of other diseases. This study was restricted to the Greater Giyani district in the Lowveld Region of the Limpopo Province in the Republic of South Africa. It was contextual because individuals within a specific cultural group served as samples for obtaining data. 


\section{Population and sampling}

The term 'population' refers to the entire number of units under study. All the inhabitants living in a specific area are the population (Treece \& Treece, 1986: 215). The population for this study consisted of all the Vatsonga residing in the following villages: Makosha, Nkuri, Mageba and Nhlaneki in the Greater Giyani district of the Limpopo Province of South Africa.

Polit \& Hungler (1995:174) describe sampling as a process of selecting a portion of the population to represent the entire population in the study. In this study, sampling of the villages and informants was done. The purposive sampling technique was used to select the villages. These villages were selected purposely because:

- $\quad$ villages with the highest number of children admitted with complications of measles were selected.

- The chosen villages are far from the hospitals and clinics.

The snowball-sampling method was used to select key informants. Key informants consisted of Vatsonga people who have cared for children with measles at home. Nine key informants were selected. The sample size was determined by saturation of information. Inclusion criteria for the sampling of key informants included that the respondent had to be Tsonga by birth, must have nursed a child with measles and had to be above the age of 50 years, who had general knowledge about the care of a child with measles.

\section{Data collection}

Data was collected using individual interviews, field notes and observation. Three sessions of individual interviews were conducted with key informants and two sessions of focussed group were conducted with general informants. Field notes were taken and a tape recorder was used to record the experiences of the Vatsonga to ensure accuracy. Observation of non-verbal cues was done to observe expressions that were not verbalised.

A static camera was used to take pictures of demonstrations such as cultural ceremonies and breaking of the pot. Reflection was done to check the correctness of information. A broad question was asked as a point of departure and more questions were generated by the discussions. The question used to collect data was 'How do the cultural health practices of the Vatsonga influence the care of children with measles at home?'

\section{Data analysis}

Data was analysed using Leininger's (1991:19) phases of analysis for qualitative research. This method was chosen because it allows interface check of information to preserve the 'emic' data and to confirm findings by checking back on the findings of each phase. Data analysis was done continuously as data was being collected. Regular data coding, processing and analysis was done until all data was collected (Leininger, 1991:95).

\section{Trustworthiness}

Trustworthiness is a method of establishing or ensuring rigour in a qualitative research without sacrificing relevance (Lincoln \& Guba, 1985:161). The researcher strove towards the principle of trustworthiness throughout the research process. Trustworthiness was ensured because the researcher has satisfactory knowledge of the research design used. Different methods were used in collecting data and the researcher was trained on how to conduct interviews. Reflections were done continuously during the interview and the researcher went back to the respondents to verify information. The four criteria used to ensure trustworthiness are truth value (credibility), applicability (transferability), consistency (dependability), and neutrality (conformability).

\section{Ethical considerations}

The informants were assured of confidentiality. Informed consent was obtained from all participants and this ensured voluntary participation. Permission to gain entrance to the villages was obtained from the chiefs and Transitional Local Council structures.

\section{Presentation, discussion of findings and literature control}

The results presented are written in the manner in which the condition presented itself and the manner in which the informants gave information. Table 3.1 shows the overview of themes, sub-themes and categories that were identified from the respondents' description of the care of children with measles at home.

\section{Vatsonga people's view of measles.}

Informants stated that they have a wealth of information regarding caring for children with measles. They added that they do not need to send the child to the traditional healer because they can manage the disease themselves. Most of the informants showed understanding of what measles is. The way in which measles has been defined by most of the Vatsonga is the same as the way in which it has been defined in the literature. Measles has been defined as an infectious disease (Kassner, 1998:104) ; (Nzimande, 1994:87). The Vatsonga also indicated that measles is infectious because it normally spreads through the whole neighbourhood.

Measles was defined in different ways by different informants. One general informant defined measles as follows: '(Ximungwa-mungwana I vuvabyi bya ntumbuluko) measles is a natural disease'. Measles is regarded as a natural disease, from which each child should suffer. This definition indicates that in the Vatsonga culture there are dis- 
Table 3 Themes, Sub - Themes and Categories

\begin{tabular}{|c|c|c|}
\hline THEMES & SUB-THEMES & CATEGORIES \\
\hline \multirow[t]{2}{*}{$\begin{array}{l}\text { Vatsonga people's view of mea- } \\
\text { sles }\end{array}$} & Vatsonga's definition of measles. & $\begin{array}{l}\text { Measles is a horrible disease because it } \\
\text { kills and it has many complications. } \\
\text { Measles is an infectious disease that each } \\
\text { child should suffer from. } \\
\text { Measles is a God-given disease that one } \\
\text { cannot dodge. }\end{array}$ \\
\hline & $\begin{array}{l}\text { signs and symptoms } \\
\text { complications of measles. }\end{array}$ & $\begin{array}{l}\text { The following signs are associated with measles: } \\
\text { - } \quad \text { Hot body } \\
\text { - } \quad \text { Shivering } \\
\text { - } \quad \text { Rash } \\
\text { - } \quad \text { Red eyes } \\
\text { - } \quad \text { Loss of appetite } \\
\text { - } \quad \text { Vomiting } \\
\text { - } \quad \text { Sleeping } \\
\text { The complications are: } \\
\text { - } \quad \text { cracked lips } \\
\text { - } \quad \text { cataract } \\
\text { - } \quad \text { loss of speech } \\
\text { - } \quad \text { diarrhoea and death }\end{array}$ \\
\hline $\begin{array}{l}\text { Vatsona's cultural management } \\
\text { of measles }\end{array}$ & Restrictions & $\begin{array}{l}\text { - Sexual intercourse is restricted between } \\
\text { partners in times of sickness. } \\
\text { The child is taken off the breast as s/he is } \\
\text { cared for by old women. } \\
\text { The child is not allowed to cross paths } \\
\text { and is restricted to the home environment. } \\
\text { Access to the sickbay is restricted to peo- } \\
\text { ple believed not to be sexually active. }\end{array}$ \\
\hline \multirow[t]{4}{*}{$\begin{array}{l}\text { Cultural preventive measures } \\
\text { against the spread of infection }\end{array}$} & Isolation & $\begin{array}{l}\text { Children are isolated and restricted in the } \\
\text { sickbay. } \\
\text { Access to the sickbay is sometimes al- } \\
\text { lowed to siblings so that they become } \\
\text { immune }\end{array}$ \\
\hline & Diet & $\begin{array}{l}\text { - The diet that is given to the child includes } \\
\text { warmed goats' milk or warmed donkeys' } \\
\text { milk mixed with donkey droppings. Any } \\
\text { type of food is given as tolerated }\end{array}$ \\
\hline & Rituals & $\begin{array}{l}\text { The highlight of management is the cul- } \\
\text { tural ceremony that includes smearing of } \\
\text { medication on the skin and breaking of } \\
\text { the earthenware pot. People are not al- } \\
\text { lowed to look back after the ritual as look } \\
\text { ing back will make them ill. }\end{array}$ \\
\hline & Isolation & $\begin{array}{l}\text { Siblings are allowed to have contact with } \\
\text { the sick child so that they become im- } \\
\text { mune. } \\
\text { Breaking the pot after the ritual which } \\
\text { leaves the disease at the crossroads and } \\
\text { the person who steps on it will carry the } \\
\text { disease with their feet to their destina- } \\
\text { tion. }\end{array}$ \\
\hline
\end{tabular}


eases that simply appear and they heal on their own. This understanding of measles could have serious implications for children. It may be ignored as the condition is regarded as normal. This definition is supported by Ijsselmuiden (1983:361) and Vlok (1996:35) who also defined measles as God-given and natural, and essential for normal development. In a study conducted among the traditional Navajo people, it was identified that acute illness and discomfort are always ignored because they are regarded as part of life. This belief attributes to late admissions of children suffering from measles in the clinics or hospital (Fahy, 1994:227).

In a study conducted in India, the villagers were said to believe that diseases like measles, smallpox and marasmus are caused by supernatural powers (Machanda, Kumar \& Bhatnagar, 1979:70), and this view is different from what the Vatsonga believe. Some informants, however, defined measles as a horrible disease. Measles was regarded as horrible because if it is not treated it could lead to complications and death. It is also indicated in the literature that the mortality rate of children under the age of three is high (Nzimande, 1994: 89). Measles was also defined by informants as an infectious disease, from which each child should suffer. One informant defined measles as follows:

'It is an infectious disease from which each child should suffer. It normally comes during winter and it spreads through the whole neighbourhood'. This definition is supported by Nzimande (1994:87) and Kassner (1988:104) who also defined measles as an infectious, contagious, notifiable disease.

Vatsonga have knowledge regarding the identification of measles in children. Informants associated the identification of measles with pain. The mood in the area of data collection changed from that of happiness to a more serious one. Informants mentioned that the occurrence of measles was unpleasant for the child and the mother. Data shows that the mother is always affected because most of the time the child does not want to eat or suck from the breast which might be caused by sores in the mouth. Informants thought the child was suffering because the first sign of the disease is a lack of activity. The child sleeps most of the time and does not want to play. One informant said that: 'Measles is an unpleasant disease which often makes the child to be sleepy and refuse to feed and this always troubles the mother.' Another informant said when describing the signs and symptoms:

'On coming back from the fields after having left the child early in the morning at about half past four, I tried to feed my child and he refused to eat and was irritable. I tried to check what was wrong, the skin felt hot to touch and he had fine rash on the cheeks, the eyes were red and the child was coughing. I knew straight away that my child had measles.'

The description of the signs and symptoms by Vatsonga is similar to the description that was found in the literature by Nzimande (1984:88); Kassner 1998:104) who indicated the following signs and symptoms: light macular rash, catarrhal inflammation of the eyes and respiratory tract, conjunctivi- tis, rise in temperature, general malaise, nausea, vomiting, diarrhoea and abdominal pain, dry cough and chest pain. Milombyani is another sign which has been described by Vatsonga. Milombyani is described as the stage in which the child shivers and rolls the eyes and this is regarded as ( $k u$ biwa) being punished by the ancestors. It was said that the child is being punished because the parents did not abstain from sexual intercourse. This could make the parents feel very guilty especially if the child dies. (Milombyani) is treated by undressing the child and rolling him/her in ash. Milombyani could be related to convulsions which is also identified in the literature. Convulsions are said to be caused by high temperature (Vlok, 1996:40). Similarities indicated that the Vatsonga people have good knowledge of how to identify the disease (measles) and there is no way in which they can provide care to a wrongly diagnosed child.

\section{Preventative cultural management of measles}

\section{- Restrictions}

Cultural restrictions are imposed on the partners by family members. All informants mentioned that sexual intercourse was restricted when there was a child suffering from measles in the family. It is believed that sexual intercourse causes the condition of the child to deteriorate, because the whole household becomes hot (ndyangu wa hisa). The Vatsonga have a strong belief in heat as the cause of complications. Heat is associated with situations that are regarded as impure and contact with this situation makes the condition worse. The following are some of the situations that are regarded as impure:

- $\quad$ sexual intercourse;
- $\quad$ death.

One informant said: 'When the household becomes hot or is contaminated with heat, the children' $s$ condition will deteriorate and the family will have lots of misfortune.'

The association of heat with misfortune is in line with the study conducted among the Zulu people where it was found that the Zulus also consider people to be mildly polluted the day following sexual intercourse (Edwards, Cheetham, Majozi \& Lasich, 1982 :85). Other factors causing heat contamination are:

- women who are menstruating;

- $\quad$ women who have had an abortion; and

- $\quad$ people during bereavement, mothers and children after death.

Heat is also described as being a malignant and contaminating force present in all conditions of evil and badness among the Pedi (Monning, 1967:67). This indicates that the Pedi and the Zulu, like the Vatsonga, associate heat with conditions that are impure or evil. Sexual intercourse among the Pedi people is associated with (ditshila) impurity that makes the place hot, and therefore brings misfortune to the people (Monning, 1967:67). The following conditions in 
the Pedi culture are also classified as being hot:

- abortion;

- sickness and death;

- multiple birth; and

- malformed children (Monning, 1967:67).

The informants expressed some form of unhappiness when they were relating the restrictions that were imposed on them during illness. They said that this was a sort of punishment because these restrictions were imposed with each illness that occurred in the family. One informant, when expressing dissatisfaction, said: 'We were denied of having sexual intercourse with our husband every time when there was an ill person in the family and this was too strenuous for me, this also made our husbands to have extramarital affairs.' This complaint was opposed by one group which felt that the cultural restrictions imposed on the community were a control measure for married people. One informant said: 'If the couple is left without restrictions, the mother will concentrate on the father and forget to pay attention to the child, especially at night that is why the partners had to be separated.' The restrictions, according to them, helped them to remain focussed on the illness of the child.

\section{- Isolation}

The sick child is confined to bed, not allowed to go outside and the number of people coming into the hut is restricted. The reasons for keeping the child in the house are the following:

- To avoid cross infection with other children, although in some cases the child was allowed to stay with the siblings so that they could be exposed to measles as well and become immune.

- To prevent exposure of the eyes to the sun, although there was no reason given for avoiding the sun.

- To prevent bad people and wind from coming into contact with the child.

Strangers are not allowed in the sick room because they normally bring bad luck and the family is not always sure about their purity. An old person believed not to be engaging her/himself in sexual intercourse would act as a guard at the door and no adults of childbearing age were allowed inside. One respondent said:

'People who are sexually active will make the condition of the child not to improve (va nwi tshikelela) they become heavy for the child.'

Barring people from entry into the sickbay is something that is being practised by different cultural groups. Monning (1967: 67) also describes how the Pedi people place a protective stick (lepheko) across the entrance of the hut. This is also used as a sign to warn people not to enter the hut. All men and all impure women are barred from entering the hut. Shai-Mahoko (1997:111) also reported that among the Batswana people lepakwana - a stik - is placed at the door of the hut when a woman has delivered, so that people can see that entrance into the hut is restricted. Almost all of the informants stated that the child is not al- lowed to move around and cross paths as this may expose her/him to bad wind (moya wo biha) and this will make him more sick.

This is in line with literature from Kassner (1998:104) where a sick child is isolated and the number of visitors to the sick room is limited. The Vatsonga restricted the child because they wanted to prevent the spread of the disease and exposure to drafts as this could lead to complications such as pneumonia and bronchitis, which is the same as the reason for isolating the children in hospital. Some informants said that: 'When the child was sick with measles the child was taken off the breast for the period of illness to be cared for by the old lady in the family with knowledge about care of the child with measles and this was sad.'

If they were to take children to the hospital they would leave them there and visit them during specific times. They also cited the fact that they know exactly what is happening to the child every time unlike in the hospital where they would be left in the dark. It was also mentioned that when the family visits the sick child in hospital, the staff do not tell them anything regarding the progress of the child. The main role players who make decisions about the health of the child are left without being informed and this makes them sad. This could be the fact that makes Vatsonga to care for their children at home.

There are some similarities and differences in the way a child with measles is cared for at home and in the hospital. In the hospital the child is isolated and the number of people allowed in the ward is restricted. Vatsonga people also isolate the sick child and restrict the number of visitors to the sickroom. The reason for isolating the child is prevention of cross infection. The reasons for restriction of people visiting the sickbay are not the same. Vatsonga restrict people to the sickbay because if people that are hot can be allowed the condition of the child will deteriorate. Restricting visitors in the hospital to the next of kin could be a contributory factor that makes the Vatsonga unwilling to send their children to hospital.

When a child is diagnosed with measles the mother's hut or the granny's hut is chosen as a sickbay. The care of this child is entrusted to the old lady or the mother under supervision of the old lady. In the study about the 'sick child nurse', mothers were identified as being appropriate caregivers in the community (Morley, Hartman \& Klouda, 1988:13). This is an indication that many communities regard women as caregivers, including the Vatsonga. If the child is admitted to the hospital and care is given by a male nurse, these can cause problems for many Vatsonga families as males are not regarded as caregivers. The child is not allowed to lie on her/his back. The child is only allowed to lie on the side. One of the respondents said: 'If the child is allowed to sleep on her/his back the rash will go inside and affect the internal organs (swirhumbani swi ta wela endzeni swi mbembemela) and makes the child to complicate.'

\section{Diet}

The food/diet that is given to the child includes everything 
that the child can tolerate, with goats' milk as the main diet. Only one group of informants cited donkeys' milk as the main diet. One informant said that the goats' milk is mixed with goat droppings. The milk is heated and given to the child while still warm. It is believed that the heat from milk removes the rash from the inside, making it appear more on the outside, and this reduces the chances of complications. Warm goats' milk is also applied to the eyes of the child to prevent cataracts from developing. Another informant said: 'Goat milk is regarded as good treatment because, if a child is given goat milk the disease will not last for more than five days'.

According to the western health care system, the milk diet is regarded as being rich in protein, which can be good for repairing worn out tissue. It should also be borne in mind that blindness, which is said to be a complication of measles, could be caused by deficiency of nutrients like vitamin A, which is good for the prevention of blindness. A balanced diet with Vitamin A supplements should be given to the children (Nzimande 1994: 90).

\section{- Rituals}

When the rash has covered the whole body and the mouth of the rash is red, it is regarded as the end of the disease. A cultural ceremony is conducted to mark the end of the disease. The child is usually woken up early in the morning before sunrise. The child is then taken to the crossroads or on top of an anthill. The leaves and small branches of the nhlangulo tree are ground in a traditional clay pot. The ground leaves are mixed with ochre and water. The mixture is then rubbed on skin of the child so that the rash is crushed and opened. The informants frowned as they were explaining this and this is a sign that they regarded skin rubbing as painful. One informant said: 'The skin was rubbed until the red mouth of rash was open and this was painful for the child because the child will be crying when being rubbed.' During the performance of the ritual the child is undressed so that every part of the body is rubbed with the mixture of ochre and leaves from the nhlangulo tree. The child is instructed to face eastwards while being rubbed with the mixture of ochre and leaves of the nhlangulo to prevent a recurrence of the disease. The traditional clay pot with the mixture is then broken after the application. The traditional clay pot, together with the mixture of ochre and leaves of the nhlangulo tree, is left at the ritual site, i.e. at the crossroads.

It is believed that the person who steps on the pieces of the broken pot will contract the disease and take it along to her/his destination and in this way the disease will leave the village. The sick child, together with the people who performed the ritual, returns home. None of the people from the ritual site should look back, as this can bring back the disease. The sick child then remains smeared with the mixture for one night.

The following day, the child is allowed to bath in warm water. Goat's milk is given to facilitate healing. The skin will start to peel, and pigs' oil is applied to soften the skin. Isolation and restrictions placed on sexual intercourse are lifted on the day of the ritual because the child can no longer suffer complications of the disease.

The cultural ceremony performed by the Vatsonga people could be similar to the terminal disinfection normally performed by nurses when a patient with an infectious disease is discharged from hospital (Vlok, $1996: 383$ ). This is a way of rendering the patient free from infection. The ceremony among the Vatsonga people is a way of trying to rid the child of infection and passing the disease to other villages. The difference between the cultural ceremony and terminal disinfection is that the hut that is used as a sickbay is not disinfected after the course of illness, while in terminal disinfection the room and utensils used by the sick person are also disinfected (Vlok, $1996: 383$ ).

\section{Complications of measles as identified by the Vatsonga}

The following are the complications that were identified by Vatsonga people. Respondents stated that measles is a dangerous disease, which if not treated properly, can cause death. The prevention of death is influenced by compliance with the restrictions imposed on the family during the course of illness. The informants also gave information about the cause, management and the measures that can be taken to prevent complications. Complications that were listed by the informants included cracked lips, cataract, rash affecting internal organs, loss of speech, deafness and death. It is believed that these are caused by not taking enough fluids and food. 'If the child has cracked lips we use pigs' oil to apply on the lips and they become healed.' Informants believed that cataract develops when the child is left outside in the sun. Another cause of cataract is when the child is left to lie on her/his back. All the informants agreed that warm goats' milk must be applied to the eyes so that the rash can be cleared from the eyes. Some informants cited the fact that juice from the aloe can be applied to the eyes to clear the cataract. Only one respondent cited that: 'In order for cataract to be removed a leaf of mbhandzu tree is used, the caretaker makes a hole on the leaf and blows air through the hole onto the eye and the cataract will be healed'.

Vatsonga people believed that blindness is caused by looking directly into the sun. It is also caused by a rash in the eyes. One informant said: 'When the eye is affected, it usually swells and thereafter the child becomes blind'. Informants believe that the rash can disappear from outside and affect the internal organs. This occurs when one continues to have sexual intercourse when the child is sick. The rash always disappears outside when one continues to have sexual intercourse in the household because the household is hot. When the rash has affected the internal organs, the child experiences difficulty in breathing or develops diarrhoea. Loss of speech, deafness and death were also regarded as other common complications of measles. This can be prevented by the use of goats' milk. All informants believed that if the rash does not come out, it affects internal organs like intestines and lungs, and death can result.

There are complications that the Vatsonga people men- 
tioned that could not be found in the literature. The only thing found in the literature that is related to deafness, is otitis media. One informant said that, "When the child is not given warm goats' milk, the rash will go inside and attack internal organs and this often leads to deafness.'

In the literature, otitis media was mentioned as one of the complications of measles (Nzimande, 1994:87) ; (Kassner, 1988:104). This is related to deafness because deafness may result from complications of otitis media. The otitis media could also be missed because the Vatsonga do not have the means of examining the ear and/or they cannot associate a sore throat with oral-pharyngeal inflammation with otitis media. Otitis media could also be missed in the earlier stages as the Vatsonga usually wait for a discharge to come out of the ear, as this is regarded as a sign of ear problems. This late identification of ear infection might lead to deafness.

\section{Cultural preventive measures against the spread of the disease}

The Informants expressed trust in the preventive measures that they use. They seemed confident and they were more than willing to share their way of preventing measles. One respondent said that 'measles can be prevented because if the caregiver ensures that sick child stays indoors and the other children do not come into contact with the sick child the other children will not contract the disease, you know even Europeans at the hospital do use some of the preventive methods used by us at home which is an indication that we have knowledge of how to care for children with measles.'

The following preventive measures were identified:

- Isolation of the child. This was achieved by not allowing the sick child to mix with well children, and by confining the child to the room.

- Advising people not to look back after the ritual because looking back might cause the disease to recur.

- $\quad$ Breaking the traditional clay pot at the crossroads is also a way of taking away the disease from the village so that whoever walks on the broken traditional clay pot will carry the disease with them, and the disease is transferred to other people/villages.

One informant said, 'if you find a broken clay pot at the cross roads you should know that a cultural ceremony was conducted to mark the end of the disease. You should make sure that you do not step on top of the broken pieces of clay pot as this will make you to take the disease to your area of destination.'

\section{Recommendations or guidelines for culturally congruent care}

Leininger's (1991:43) three modes of decision and action have been adapted and used to make recommendations and offer guidelines that can be used in the professional health setting or traditional health settings where the Vatsonga people care for a child with measles. The researcher drew upon the findings from the informants regarding the Vatsonga world-view, social structure and folk professional values and practices, to identify care actions and decisions as in Leininger's theory.

In caring for the clients, the nurse needs to understand the cultural values and health practices of the Vatsonga in caring for children with measles. Decisions and actions taken should aim at attaining culturally congruent care. The three modalities are next discussed in relation to the findings on the care of children with measles by the Vatsonga and as quidelines for care that can be given by the nurse (Leininger, 1991:43).

\section{Cultural care preservation and maintenance}

In providing cultural care preservation and maintenance, the cultural values and beliefs of the Vatsonga people that gives them a sense of protection, security, and cultural identity is maintained. These dimensions need to be considered and respected by the nurse in providing congruent care that will be beneficial and satisfying to the people being served. Preservation of cultural care needs to be considered by not forcing the Vatsonga into the professional health care system that they are not used to. Instead, care should be offered in ways that can make hospitalisation congruent and beneficial to their folk traditions and values. Expectations related to the cultural rituals, and group kin presence would need to be maintained while in hospital or in home care. The use of other care methods by family, clan members and others in the world would be very important.

- $\quad$ Restrictions that are imposed on the child should be maintained. The practice of not allowing the child to cross paths and isolation of the child need to be preserved as these will assist in controlling the spread of infection and provide protection to the eyes. Health professionals should give health advice to the Vatsonga people on how the infection occurs and the mode of spreading. The knowledge that the Vatsonga have with regard to complications should be preserved. They should be given more information on how these complications can be prevented.

- The involvement of key role-players in decisionmaking should be maintained. Important people who make decisions within the family should be well informed about the progress of the child, and should be allowed to contribute to decision-making regarding the welfare of their children. Should the condition of the child permit, it would be better to work in a familiar environment as this is a fundamental transcultural principle that needs to be respected amid some risks at times. The community nurse can achieve much by doing home visits daily until the risky period has passed.

- Cultural care accommodation and negotiation will 
be the major mode of nursing care when the nurse works with the Vatsonga, because of the strong belief in taboos among the Vatsonga. The cultural practices and taboos of the Vatsonga need to be respected and accommodated, especially if they do not cause any harm.

- Barring partners from engaging in sexual intercourse could be accommodated. The belief that sexual intercourse among couples should not be practised when the child is ill needs to be accommodated. This belief should be negotiated and with the permission of the people involved, the practice can be accommodated because it has a lot of meaning in the culture of the Vatsonga. However, the Vatsonga should be warned against this practice as partners can have extramarital affairs and this can expose them to sexually transmitted diseases like HIV.

- Restrictions on the number of people allowed in the sickbay should be accommodated. During care at home by the Vatsonga, the practice of restricting the number of people in the sickbay should be encouraged. This will assist in preventing people with different infections from visiting the sickbay. The Vatsonga could be advised on the importance of avoiding infection, as the child's resistance is low during illness.

- Breaking the pot during the cultural ceremony could be accommodated.

The prevention method that is practised by the Vatsonga people, of not looking back when coming from the cultural ceremony and breaking the pot can be accommodated because it does not cause harm to anybody. The practice gives the Vatsonga people a sense of relief, as this is associated with a way of taking the disease out of the village.

\section{Cultural care repatterning and restructuring}

This refers to those caring methods used to help an individual or group to make some major structural changes related to unhealthy practices, or practices that are not beneficial. This will be difficult if the Vatsonga people distrust the nurses. Trust should first be established by nurses through maintenance of some cultural care practices as well as by accommodation modes before repatterning. The following practices should be restructured:

- Diet;

- Rituals; and

- Instillation of aloe juice in the eyes.

- The use of a milk-only diet could be changed.

Dietary requirements are one of the aspects where the Vatsonga should be persuaded to change. The Vatsonga should be taught about the importance of a balanced diet for the child. They should be advised to add more nutrients to the diet. Giving milk only to the child will not provide her/him with a balanced diet. The importance of including vitamin A, which is essential in the prevention of blindness, should be emphasised.
Mixing goats' milk with droppings should be discouraged.

The practice of mixing milk with goats' droppings should be discouraged. The Vatsonga should be made aware of the different diseases, like tetanus, that one can get from droppings (vulongo). The importance of good personal hygiene should be emphasised. The Vatsonga may need to be educated about tetanus, its causes, signs, symptoms and complications.

\section{couraged.}

Restrictions imposed on the mothers regarding taking their children off the breast to be cared for by the granny should be discouraged. The Vatsonga need to be educated in relation to the importance of breast-feeding and the dangers of taking the child off the breast because it lowers the child's resistance to infection. Mothers need to be educated about the advantages of breast milk.

\section{- Use of juice on the children's eyes needs to be changed. \\ The Vatsonga use juice from the bark of the aloe tree to treat conjunctivitis and prevent blindness. This could be dangerous to the eyes as the eyes are very sensitive or- gans. The Vatsonga people could be convinced through negotiation to use a prescribed ointment. The dangers of using unprescribed treatment on the eyes should be ex- plained to the Vatsonga.}

- Rubbing the skin of the child until the mouth of the rash opens should be discouraged.

During the cultural ceremony the leaves of the 'nhlangulo' are used together with ochre to apply to the skin. The Vatsonga should be educated about the dangers of rubbing the skin until the mouth of the rash opens up. This is a dangerous practice because it can be a route through which HIV can be introduced to the child or the person performing the ritual if there is bleeding and laceration. The people should be taught about the dangers of coming into contact with blood, especially when they have wounds or lacerations.

\section{- Alterations regarding the time of performing a cultural ceremony,}

The cultural ceremony is usually conducted in the morning. The Vatsonga could be advised to perform the ceremony when it is warm so that the child is not exposed to drafts and allowed to catch cold. This should be stressed to avoid complications such as pneumonia and bronchitis. More information regarding respiratory infections should be taught to the Vatsonga so that they could detect the signs of infection earlier to avoid complications.

\section{- Attributing the occurrence of convulsions to wrong- doing should be discouraged.}

The Vatsonga always attribute the occurrence of convulsions to wrong-doing. This belief needs to be changed as it normally leaves parents with feelings of guilt. The Vatsonga need to be educated about the causes of convulsions and how to treat them when they occur. The practice of rolling 

Figure 4.1 explains how the Vatsonga and
health profesionals can work together

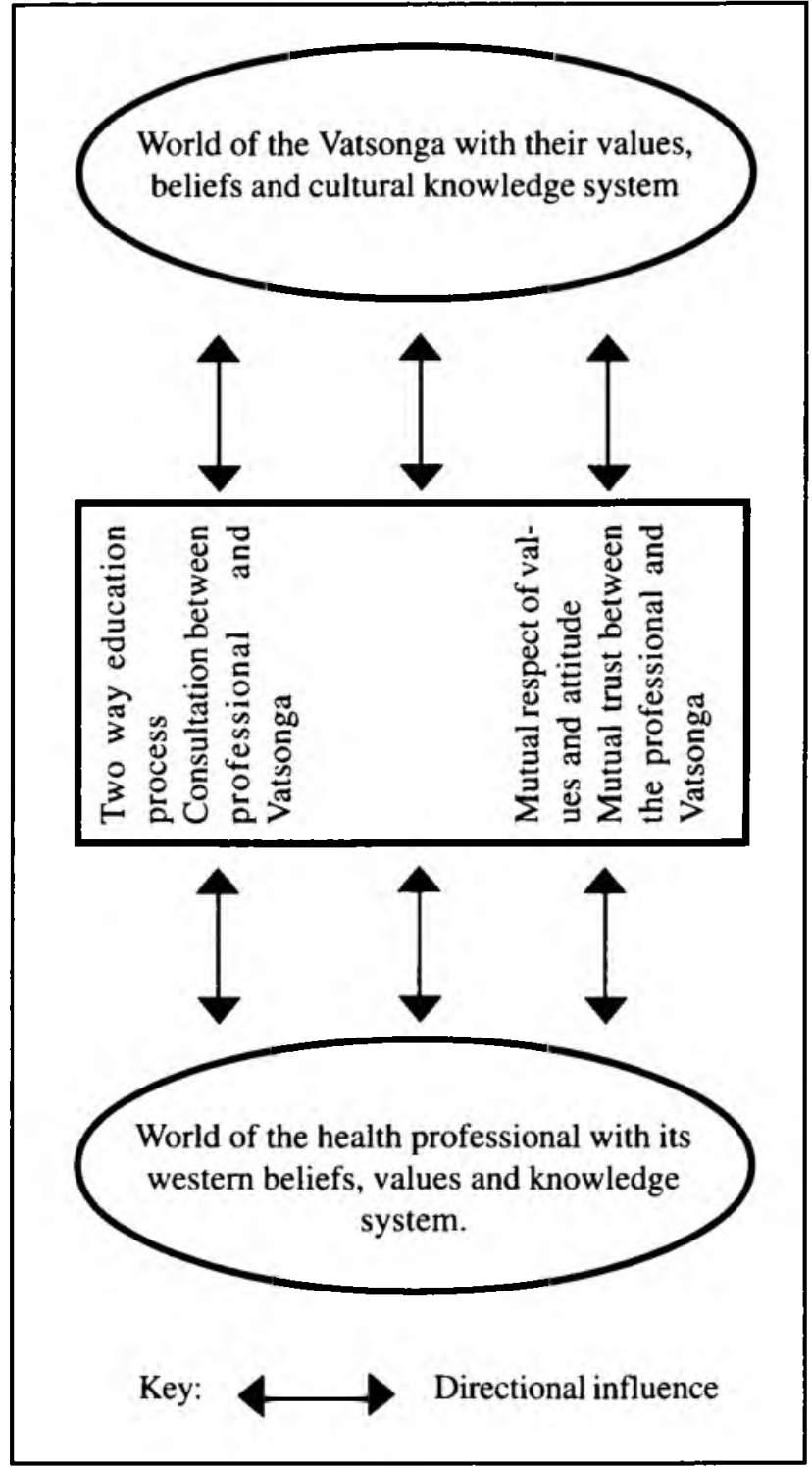

the naked child on ash in the rubbish pit should be discouraged. The child can be infected or even burned if the ash is still hot.

Cultural care repatterning should be done with the client, using creative thinking for beneficial outcomes. The active participation of the client and their family is very important. Most important is that the nurse should have the client as an active participant in the planning and implementation of professional nursing care with respect to the emic care needs and ways of life to regain health and to build confidence and trust with them.

Throughout the nursing action or decision-making using accommodating or repatterning strategies, the nurse needs to be knowledgeable about the world-view and the social structure of the Vatsonga. This will help the Vatsonga in making informed decisions. Working with the Vatsonga's extended family within their environment would also need to be considered especially with the introduction of homebased care. While there are additional care practices that could be discussed, it will be for the nurse to consider as $\mathrm{s} /$ he works with the Vatsonga in the Greater Giyani district or elsewhere in the world. Cultural variations among the Vatsonga could also be possible and that should also be kept in mind.

\section{Co-operation between health professionals and the Vatsonga}

To successfully promote co-operation and co-ordination of services between the Vatsonga and health professionals, the following should be observed:

- $\quad$ Respect - Both the Vatsonga people and health professionals should respect each other's values, beliefs and attitudes.

- $\quad$ Trust - there should be a relationship of trust among the Health professionals and the Vatsonga.

- Education - education should be a two-way process between the Vatsonga and health professionals.

- Consultation - there should be consultation between the Vatsonga and health professionals. The Vatsonga people should feel free to come to the health service to seek advice when they care for sick children at home. If the child is admitted to hospital the health professionals should seek advice from the family members.

\section{Limitations of the study}

- This study was conducted in one district, and the Vatsonga living outside the Greater Giyani District could not be reached.

- The villages selected were within $200 \mathrm{~km}$ radius of the researcher's residence and the Vatsonga people living outside the $200 \mathrm{~km}$ radius could not be reached.

- Lack of funds and facilities made it impossible for the researcher to stay in the villages for a longer time where more observations of care during the night could have been made.

- Walking in the villages was difficult, as the roads had been damaged during the floods and this made it impossible to reach some areas in the village.

- $\quad$ People belonging to focus groups that were interviewed at the pension pay points, did not participate fully because they were anxious about getting their pension grants.

\section{Conclusion}

Nurses must continue to study the neglected and unknown cultures as they continue to build trans-cultural knowledge to guide nurses in our changing world. From this study one should appreciate the knowledge and courage of the Vatsonga in preserving and maintaining what they value. Although this is a culture that the nurses cannot readily 
change, it is a culture that nurses are challenged to respect and understand as the Vatsonga people's human right.

\section{Recommendations for further research}

To date, limited research has been done on the subject of the home care of children with measles using the transcultural approach, and there is very little literature on the subject. The study has left many unanswered questions, such as the following, and are suggested for research:

- a comparative study that will look at the home care of children with measles among the different ethnic groups.

\section{References}

BRINK, PJ \& WOOD, M J. 1994: Basic steps in planning nursing research, from Question to proposal. 4th Edition. Boston: London. Jones and Bartlett Publishers.

BOYLE, JS \& ANDREWS, MM. 1995: Transcultural concepts in nursing care. London. Scott, Foreman and company.

BURNS, N \& GROVE SK. 2001: Practice of nursing research, conduct, critique and utilization. Philadelphia: W.B Saunders.

EDWARDS, SD, CHEETHAM, RWS, MAJOZI, E \& LASICH AJ. 1982: Zulu culture-bound psychiatric syndromes. Journal of medicine. South African medical journal 8(63): $80-99$.

DEPARTMENT OF HEALTH STATISTIC. 2002. Statistical notes, vol 12 no 19.

FAHY, ET. 1994: Transculturalism: Still winking and speaking in code. Nursing and health care. National league for nursing. 15(5): 227-240.

GALE, GW. 1934: Native medical ideas and practices in relation to native medical services. Journal of medicine. South African medical journal. 8(3): 250-259.

GELFAND, M. 1980: African customs in relation to preventive medicine. Journal of medicine. Central African journal. 12(4): 234-240.

IJSSELMUIDEN, CB. 1983: Beliefs and practices concerning measles in Gazankulu, Joumal of medicine. South African medical journal. 10(8): 230-267.

KASSNER,C. 1998: Communicable diseases in the African continent. Durban. Bramprint (pty) Ltd.

KIBEL, MA \& WAGSTAFF, L A. 2001: Child health for all. A manual for Southern Africa. Cape Town. Oxford university press.

KREFTING,I. 1991: Rigor in nursing, the assessment of trustworthiness. American Journal of Occupational Therapy. 45(3): p214-222

KRIEL, KD, \& HARTMAN, JB. 1991: Khindlimukani vatsonga. The cultural heritage and development of the Shangana-Tsonga. 1 st edition.Silverton: Pretoria. Promedia printers.

KRUEGER, RA. 2000; Focus group - a practical guide for applied research. 2nd edition. London: Sage.

LEININGER, MM. 1991: Culture care diversity and universality: A theory of nursing. 350 Hunderson street: New York. National league for nursing press.

LINCOLN, YS, \& GUBA, EG. 1985: Naturalistic enquiry. London: Sage.

MANCHANDA, KS KUMAR, V \& BHATNAGAR, V. 1979: Understanding of disease and treatment seeking pattern of childhood illnesses in rural Haryana India. Tropical and Geographical Medicine. 12(2): p70-76.

MONNING, HO. 1967: The Pedi. Pretoria: J. L. Van Schaiks limited.

MORLEY, D HARTMAN, P \& KLOUDA, T. 1988: The sick children's nurse. Nursing RSA Verpleging. 3(2):p 321340 .

MORSE, JM \& FIELD, PA. 1996: Nursing Research, The application of qualitative approaches. United Kingdom: Stanley Thornes Ltd.

MYBURG,CPH \& POGGENPOEL M. 1995: Qualitative Research Strategy: and what now?. Rand Afrikaanse University. South Africa.

NZIMANDE, PN. 1994: Communicable diseases in South African. 2nd edition. Kwadlangezwa: Empangeni. Natal. RSA. Alberts publisher.

LIMPOPO PROVINCE HEALTH STATISTICS. 1999: Hospital statistics. Nkhensani hospital. Lowveld Region

PARSE, RR. 1996: Building knowledge through qualitative research. The road less travelled. Nursing as a science quarterlv. 9(1): p10-16.

POLIT, DF \& HUNGLER, BP. 1995: Nursing Research. Principles and methods. 4th edition. Philadelphia: J B Lippincott Company.

SHAI-MAHOKO, SN. 1997: The role of indigenous healers in disease prevention and health promotion among the black South Africans: A case study of the Northwest Province. South Africa: Pretoria: South Africa.

STREUBERT, HJ \& CARPENTER, DR. 1995: Qualitative research in nursing-advancing the humanistic imperative. Philadelphia: JB Lippincott. 
TREECE, EW \& TREECE, JW. 1986: Elements of Research in nursing. 4th Edition. St Louis C.V. Mosby Company.

VLOK, ME. 1996: Manual of nursing, community and communicable diseases a textbook for South African students. Cape Town: Juta \& Co, LTD. 